\title{
UPAYA PENINGKATKAN HASIL BELAJAR KAYANG SENAM LANTAI MELALUI METODE PEMBELAJARAN TUTOR SEBAYA
}

\author{
${ }^{1}{ }^{2}{ }^{2}$, Dini Firman Hidayahan ${ }^{3}$
}

email: yudhipurnama@unwahas.ac.id ${ }^{1}, \underline{\text { lusiana@ }}_{\text {unwahas.ac.id }}{ }^{2}, \underline{\text { dinifirmanhiyaday15@gmail.com }}^{3}$

\author{
1, 2,3 PJKR FKIP Universitas Wahid Hasyim
}

\begin{abstract}
Abstrak
Pendidikan jasmani adalah proses pembelajaran melalui aktifitas fisik untuk meningkatkan kebugaran jasmani, mengembangkan keterampilan gerak dan pengetahuan serta perilaku hidp sehat. Hasil belajar siswa materi kayang senam lantai masih rendah, hal ini diketahui dari hasil observasi peneliti saat praktik mengajar. Tujuan dari penelitian ini adalah untuk meningkatkan hasil belajar kayang menggunakan metode turor sebaya. Jenis penelitian yang digunakan adalah penelitian tindakan kelas yang terdiri dari 2 siklus. Masing-masing siklus terdiri dari kegiatan perencanaan, pelaksanaan tindakan, observasi, dan refleksi. Penelitian dilakukan di MA NU 03 Sunan Katong Kaliwungu Kendal Jawa Tengah, dengan populasi penelitian kelas XI IPA dengan jumlah 34 siswa, 11 anak putra dan 23 anak putri, teknik penarikan sampel menggunakan total sampling. Instrument penelitian yang digunakan yaitu lembar observasi keterlaksanaan pembelajaran, dan tes keterampilan. Hasil penelitian menunjukkan bahwa ada peningkatan nilai dari pra siklus rata-rata nilai 67 dan 29,41\% tuntas, meningkat pada siklus 1 nilai rata-rata sebesar 73 dan 50\% tuntas, dan siklus II nilai rata-rata meningkat menjadi 76 dan 85,29\% siswa tuntas. Simpulan penelitian ini adalah model pembelajaran tutor sebaya dapat meningkatkan hasil belajar siswa materi kayang senam lantai.
\end{abstract}

Kata Kunci: Hasil Belajar, Kayang, Tutor Sebaya

\begin{abstract}
Physical education is a learning process through physical activities to improve physical fitness, develop movement skills and knowledge and behavior of healthy lives. The learning outcomes of students with floor exercise material are still low, this is known from the results of observations of researchers during teaching practice. The purpose of this research is to improve the learning outcomes of kayang using peer-to-peer learning methods. This type of research is a classroom action research consisting of 2 cycles. Each cycle consists of planning, implementing actions, observing, and reflecting. The research was conducted at MA NU 03 Sunan Katong Kaliwungu Kendal, Central Java, with a research population of class XI IPA with a total of 34 students, 11 sons and 23 daughters, the sampling technique used total sampling. The research instrument used was the observation sheet of learning implementation and skills tests. The results showed that there was an increase in the value of the pre-cycle with an average value of 67 and $29.41 \%$ complete, an increase in the first cycle the average value was 73 and $50 \%$ complete, and the second cycle the average value increased to 76 and 85, 29\% of students completed. The conclusion of this research is that the peer tutor learning model can improve student learning outcomes like floor exercise.
\end{abstract}

Keywords: Learning Outcomes, Bridge Up, Peer Tutoring

\section{A. Pendahuluan}

Pendidikan sebagai suatu proses pembinaan manusia seumur hidup, pendidikan jasmani kesehatan yang diajarkan di sekolah memiliki peranan sangat penting, yaitu memberikan kesempatan peserta didik untuk terlibat langsung dalam berbagai pengalaman belajar melalui aktivitas jasmani, olahraga dan kesehatan yang terpilih yang dilakukan secara sistematis. Pembekalan pengalaman belajar itu diarahkan untuk membina pertumbuhan fisik dan perkembangan psikis yang lebih baik, sekaligus membentuk pola hidup sehat dan bugar sepanjang hayat. Pendidikan merupakan sesuatu hal yang penting bagi bangsa, pendidikan merupakan garda terdepan bagi anak-anak bangsa. Pendidikan di Indonesia di tuntut untuk 
mempunyai IQ tinggi dan mengesampingkan EQ, siswa di tambah banyak mata pelajaran yang menambah daya pikir tanpa memberikan hal-hal yang menyenangkan agar siswa tidak stress. Mata pelajaran PJOK merupakan bagian integral dalam pendidikan secara keseluruhan, bertujuan untuk mengembangkan aspek kebugaran jasmani, kemampuan gerak, kemampuan berfikir kritis, keterampilan social, penalaran, stabilitas emosional, tindakan moral, aspek pola hidup sehat dan pengenalan lingkungan bersih melalui aktivitas jasmani, olahraga dan keseehatan terpilih yang direncanakan secara sistematis dalam rangka mencapai tujuan pendidikan nasional (Ayu, 2018). Pendidikan jasmani suatu proses pembelajaran melalui aktifitas jasmani yang didesain untuk meningkatkan kebugaran jasmani, mengembangkan keterampilan motorik, pengetahuan dan prilaku hidup sehat dan aktif, sikap sportif dan kecerdasan emosi. Lingkungan belajar diatur secara seksama untuk meningkatkan pertumbuhan dan perkembanngan seluruh ranah jasmani, psikomotor, kognitif, dan afektif setiap siswa (Samsudin, 2008).

Pendidikan jasmani bukan hanya merupakan aktivitas pengembangan fisik secara terisolasi, akan tetapi harus berada dalam konteks pendidikan secara umum (general education). Tentunya proses tersebut dilakukan dengan sadar dan melibatkan interaksi sistematik antarpelakunya untuk mencapai tujuan yang ditetapkan. Pendidikan jasmani adalah pendidikan melalui dan tentang aktivitas fisik (Permana, 2020). Penilaian dalam pendidikan jasmani terdiri dari 3 aspek, yaitu penilaian kognitif (pengetahuan), afektif (sikap) dan psikomotor (keterampilan) (Afandi, 2020). Guru merupakan salah satu faktor yang sangat penting dalam keberhasilan proses pembelajaran. Guru pendidikan jasmani harus mempunyai kemampuan soft skills dan hard skills yang baik untuk mendidik, mengajar, membimbing, mengarahkan, melatih dan menilai serta mengevaluasi setiap peserta didik (Lusiana \& Purnama, 2019). Senam dapat diartikan sebagai setiap bentuk latihan fisik yang disusun secara sistematis dengan melibatkan gerakan-gerakan yang terpilih dan terencana untuk mencapai tujuan tertentu (Sutrisno, 2010). Sikap kayang adalah sebuah gerakan senam lantai dengan posisi kedua tangan dan kaki bertumpu pada matras dengan posisi terbalik kemudian meregang dan panggul serta perut diangkat ke atas. Manfaat dan tujuan melakukan kayang adalah untuk melatih tubuh agar tetap lentur, terutama pada bagian bahu. Namun untuk pemula diwajibkan berlatih secara bertahap, agar tidak terjadi cedera atau tulang patah saat melakukan gerakan sikap kayang ini. Kayang adalah salah satu bentuk latihan yang menjadi bagian dalam senam lantai, yaitu dengan memposisikan tubuh untuk membusur/melengkung menghadap ke atas dengan tumpuan kedua telapak kanan dan kaki. Sikap kayang sempurna bisa dilakukan jika kamu memiliki kelenturan tubuh yang bagus terutama pada kelenturan tulang belakang dan kelenturan tulang kaki. Dengan kata lain kayang adalah sebuah gerakan senam lantai dengan posisi kedua tangan dan kaki bertumpu pada mantras dengan posisi terbalik kemudian meregang dan panggul serta perut diangkat ke atas (Lusiana, 2019).

Cara melakukan kayang adalah sebagai berikut: 1) sikap permulaan berdiri dan kedua tangan bertumpu pada pinggul, 2) Kedua kaki dan siku tangan ditekuk lalu kepala dilipat ke blakang, 3) Kedua tangan iputar ke belakang sampai menyentuh matras sebagai tumpuan, dan 4) posisi badan melengkung bagai busur (Haryanto, 2012). Metode adalah cara yang dipakai oleh seseorang untuk menapai tujuan tertentu, sedangkan belajar adalah proses transformsasi ilmu antara guru dan peserta didik dari yang awalnya belum tahu menjadi tahu dan belum bisa menjadi bisa. Metode pembelajaran adalah teknik penyajian yang dikuasai oleh guru untuk mengajar atau menyajikan bahan pelajaran kepada siswa di dalam kelas, baik secarai individual ataupun kelompok agar pelajaran itu dapat diserap, dipahami dan dimanfaatkan oleh siswa dengan baik (Darmadi, 2017). Ada banyak metode dalam belajar, salah satunya dengan metode bantuan teman sebaya (peer tutoring). Belajar dengan teman sendiri dapat menghilangkan kecanggungan bagi siswa yang malu bertanya. Tutor dapat membantu teman yang belum paham, sehingga akan terjadi kegiatan belajar yang aktif, komunikatif dan menyenangkan. Metode ini memanfaatkan siswa yang lulus atau yang sudah berhasil untuk membantu atau melatih teman yang mengalami kesulitan (Sudjatmiko, 2021). 


\section{B. Metode}

Penelitian yang akan dilaksanakan ini menggunakan penelitian tindakan kelas (Classroom Action Research). Penelitian tindakan kelas (PTK) merupakan penelitian yang dilakukan oleh guru di dalam kelasnya sendiri melalui refleksi diri, dengan tujuan untuk memperbaiki kinerjanya sebagai guru sehingga hasil belajar siswa menjadi meningkat (Wardhani, 2007). Desain yang diguakan dalam penelitian ini adalah desain yang di kemukakan oleh Arikunto. Menurut (Arikunto, 2010) ada empat tahapan penting dalam penelitian tindakan, yaitu perencanan, pelaksanaan, pengamatan dan refleksi. Keempat tahapan dalam penelitian tindakan tersebut akan membentuk sebuah siklus, Jadi satu siklus dimulai dari tahap perencanaan sampai dengan refleksi. Banyaknya siklus tergantung masih atau tidaknya tindakan tersebut diperlukan, selain itu juga tergantung pada permasalahan pembelajaran yang perlu dipecahkan.

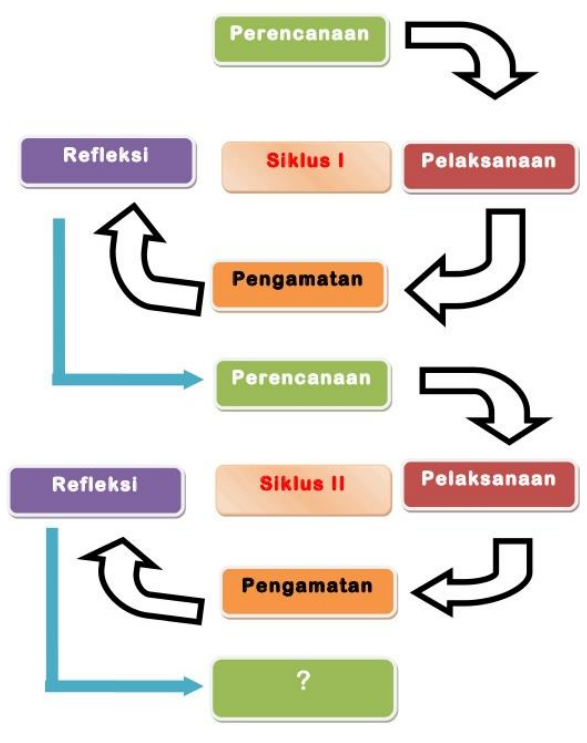

Gambar 1. Siklus Penelitian Tindakan Kelas (Arikunto, 2010)

Penelitian ini dilaksanakan dalam dua siklus, tetapi tidak menutup kemungkinan jika pada siklus kedua belum memenuhi SKM bisa dilakukan siklus berikutnya. Masing-masing siklus terdapat empat tahap, yaitu: (1) perencanaan (planning), (2) pelaksanaan (action), (3) observasi (observation), (4) refleksi (reflection).

Tabel 1. Teknik dan Alat Pengumpulan Data

\begin{tabular}{ccccc} 
No & Sumber Data & Data yang Diperoleh & Teknik Pengumpulan Data & Instrumen \\
\hline 1 & Siswa & Afektif & Observasi & Observasi \\
2 & Siswa & Kognitif & Tes siswa & Tes tertulis \\
3 & Siswa & Psikomotor & Tes siswa & Praktek \\
\hline
\end{tabular}

\section{Hasil dan Pembahasan}

Penelitian ini dilakukan di Madrasah Aliyah Nahdatul Ulama 03 Sunan Katong Kecamatan Kaliwungu Kabupaten Kendal Provinsi Jawa Tengah, dengan subyek penelitian Siswa Kelas XI IPA sebanyak 34 siswa. Dari tes awal dapat dilihat bahwa pelaksanaan pembelajaran masih belum oktimal karena nilai rata-rata mencapai 67 atau di bawah KKM yaitu 75. Dari 32 siswa hanya 10 yang sudah tuntas atau ketuntasan baru 31,25\%. 
Tabel 2. Perolehan Nilai Pra Siklus

\begin{tabular}{ccccccc}
\multicolumn{2}{c}{ Siswa } & \multicolumn{2}{c}{ Perolehan } & \multicolumn{2}{c}{ Ketuntasan } \\
\hline L & P & Nilai Terendah & Nilai & Rata-rata & Sudah & Belum \\
& & & Tertinggi & & & \\
11 & 23 & 54 & 78 & 67 & 10 & 24 \\
\hline
\end{tabular}

Setelah melaksanakan proses perbaikan pembelajaran pra siklus pada pembelajaran penjas dengan materi kayang diperoleh refleksi bahwa penggunaan metode pembelajaran yang kurang tepat, siswa kurang tertarik mengikuti KBM, gutu kurang memberikan pengarahan pada siswa yang mengalami kesulitan.

Tabel 3. Perolehan Nilai Siklus 1

\begin{tabular}{ccccccc}
\multicolumn{2}{r}{ Siswa } & \multicolumn{2}{c}{ Perolehan } & \multicolumn{2}{c}{ Ketuntasan } \\
\hline L & P & Nilai Terendah & Nilai & Rata-rata & Sudah & Belum \\
& & & Tertinggi & & & \\
11 & 23 & 63 & 80 & 73 & 17 & 17 \\
\hline
\end{tabular}

Tabel di atas menunjukkan bahwa ada peningkatan nilai terendah 63 , nilai tertinggi menjadi 80, rata-rata 67 dan yang tuntas menjadi 17 siswa atau 53,12\%. Dari data yang dikumpulkan oleh pengamat diketahui bahwa guru sudah melaksanakan pembelajaran sesuai RPP. Kurang memaksimalkan media pembelajaran dan masih banyak siswa yang belum mencapai KKM dalam mengerjakan tugas. Perlu adanya bimbingan dan motivasi terhadap siswa dalam proses KBM. Setelah melakukan proses perbaikan pembelajaran siklus I materi senam lantai kayang diperoleh data refleksi antara lain: 1) Metode pembelajaran sudah tepat, 2) Metode pembelajaran bantuan teman belum maksimal, 3) Ada beberapa anak yang masih kurang perhatian, dan 4) Ada beberapa siswa yang kurang aktif.

Tabel 4. Perolehan Nilai Siklus 2

\begin{tabular}{ccccccc}
\multicolumn{2}{c}{ Siswa } & \multicolumn{2}{c}{ Perolehan } & \multicolumn{2}{c}{ Ketuntasan } \\
\hline L & P & Nilai Terendah & Nilai & Rata-rata & Sudah & Belum \\
11 & 23 & 65 & Tertinggi & 76 & 29 & 5 \\
\hline
\end{tabular}

Tabel di atas menunjukkan bahwa ada peningkatan nilai terendah 65 , nilai tertinggi menjadi 83, rata-rata 76 dan yang tuntas menjadi 29 siswa atau 90,62\%. Proses perbaikan pembelajaran pada siklus II kayang melalui media bantuan teman sebaya diperoleh data refleksi yaitu Guru telah melaksanakan pembelajaran dengan menggunakan metode tutor sebaya dengan baik. Sehingga ada peningkatan hasil belajar yang cukup signifikan. Pelaksanaan proses pembelajaran secara umum sudah baik. Perbaikan pembelajaran sudah berhasil dengan pencapaian nilai ketuntasan belajar meningkat dari tahap pra siklus, siklus I dan siklus II. Pelaksanaan proses pembelajaran secara umum sudah baik. Perbaikan pembelajaran sudah berhasil dengan pencapaian nilai ketuntasan belajar meningkat dari tahap pra siklus, siklus I dan siklus II. Berdasarkan hasil ketuntasan belajar dapat diketahui bahwa pada pra siklus siswa yang tuntas sebanyak 10 siswa, dan yang tidak tuntas 24 siswa, pada siklus I siswa yang tuntas sebanyak 17 siswa dan yang tidak tuntas 17 siswa dan disiklus II siswa yang tuntas sebanyak 29 siswa dan yang tidak tunts 5 siswa.

Pada saat melakukan penelitian ini sebelum di beri metode pembelajaran teman sebaya para siswa takut untuk melakukan kayang dengan alaan takut cedera, tidak bisa dan lain sebagainya. Tapi setelah di merikan metode pembelajaran teman sebaya di siklus I para siswa sedikit-sedikit berani melakukan kayang, dari yang tadinya takut sedikit-sedikit keberanian itu muncul yang tadinya belum bisa menjadi bisa karna dengan metode pembelajaran teman sebaya, siswa berani karna ada teman yang membantu dan tidak akan terjadi cedera. Di siklus II pun 
masih sama pemberian metode pembelajaran teman sebaya. Dari pra siklus, siklus I, siklus II terjadi peningkatan yang signifikan dari pra siklus hanya sebesar $29,41 \%$ terdapat peningkatan di siklus I sebesar 20,59\% dan di siklus II terdapat peningkatan sebesar 35,29\%. Dari situ peneliti dapat melihat peningkatan keberhasilan yang signifikan, jadi metode pembelajaran teman sebaya untuk pemebelajaran kayang berhasil dengan prosentase akhir 85,29\%.

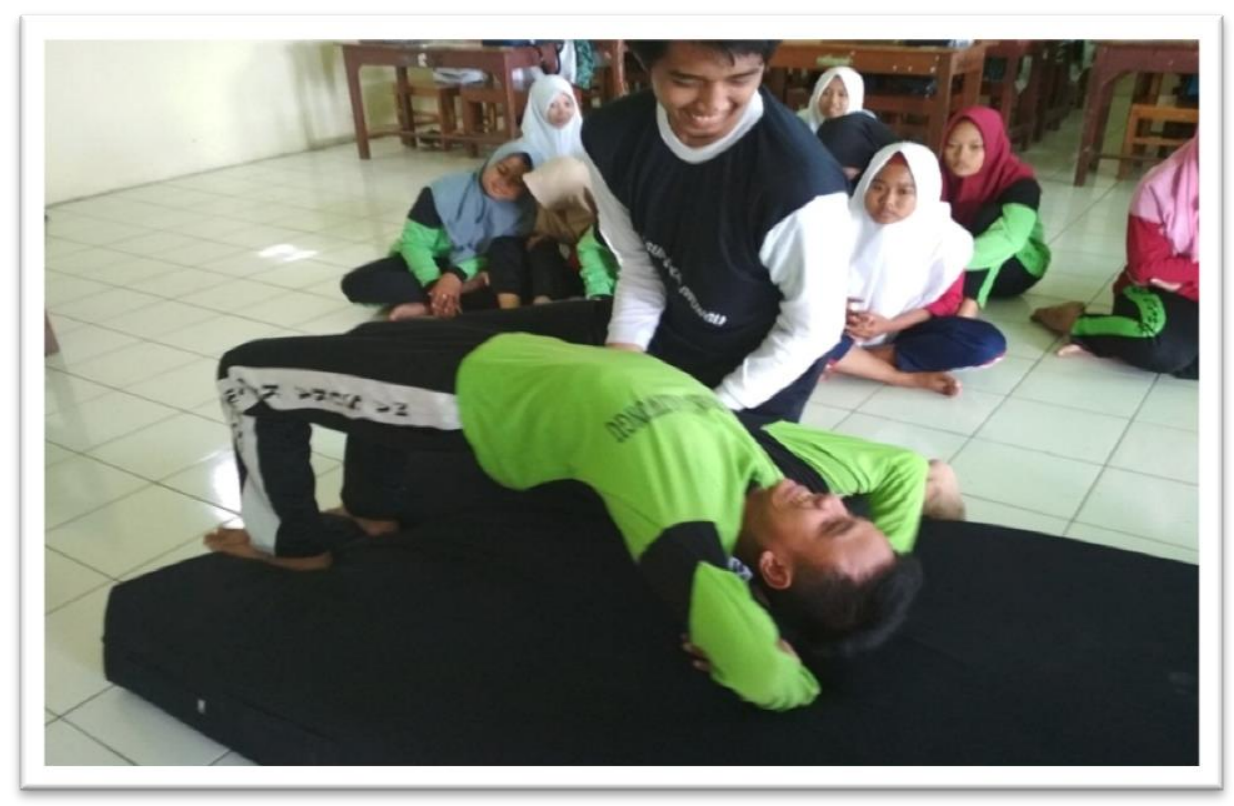

Gambar 2. Hasil Penelitian

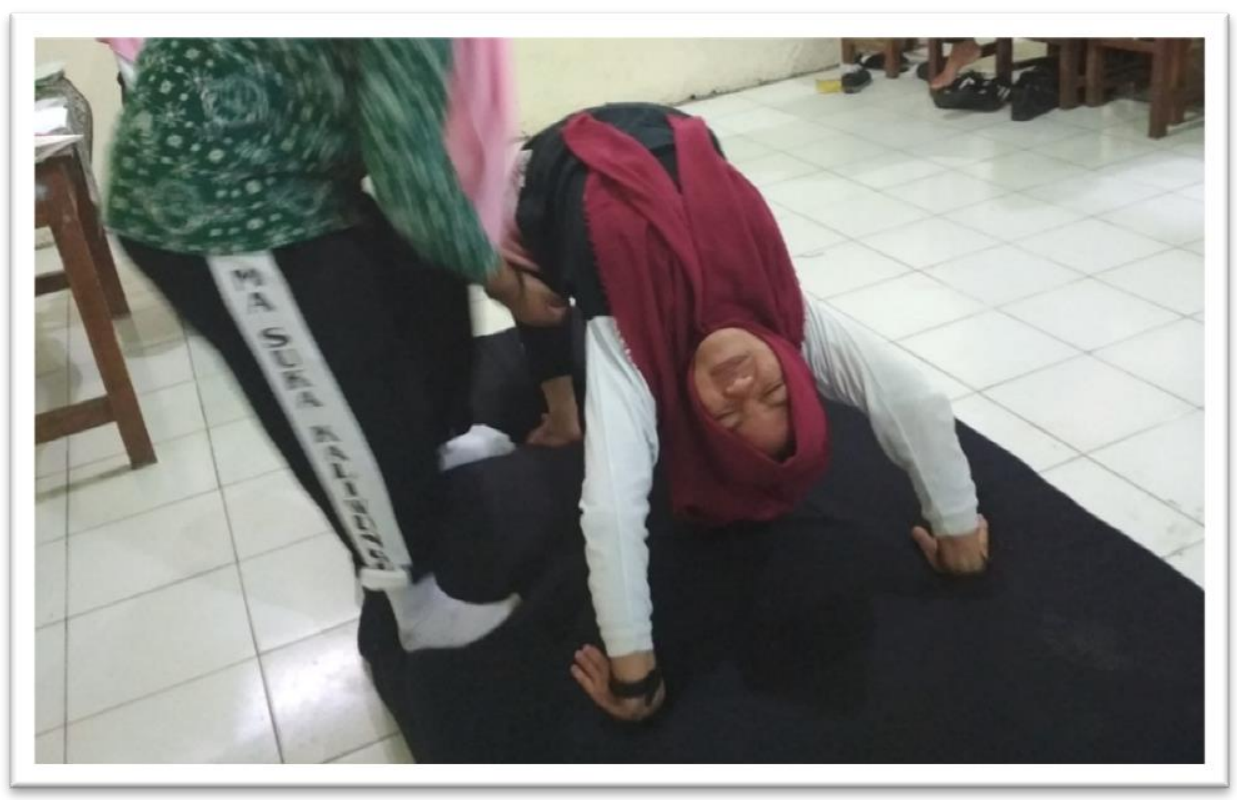

Gambar 3. Hasil Penelitian

\section{Kesimpulan}

Dari hasil penelitian dan pembahasan di atas dapat disimpulkan bahwa hasil belajar kayang senam lantai dapat ditingkatkan melalui pembelajaran dengan metode tutor sebaya pada siswa kelas XI IPA MA NU Sunan Katong Kaliwungu Kabupaten Kendal Jawa Tengah, dengan nilai rata-rata meningkat dari pra siklus 67 menjadi 73 pada siklus I dan 76 pada siklus II serta ketuntasan belajar meningkat dari 10 anak pra siklus menjadi 17 siswa pada siklus I dan pada siklus II meningkat menjadi 29 siswa.

\section{Daftar Pustaka}

Arikunto, S. (2010). Prosedur Penelitian: Suatu Pendekatan Praktik (Edisi Revisi). Jakarta: Rineka Cipta. 
Creating Productive and Upcoming Sport Education Profesional Hmzanwadi University

Vol.4, No.1, Juni 2021, Hal. 08-13

e-ISSN 2614-8781

Afandi, A., \& Faisal, M. (2020). Upaya Meningkatkan Teknik Juggling Permainan Futsal Dengan Media Alat Bantu. Jurnal Porkes, 3 (2), 142-148. https://doi.org/10.29408/porkes.v3i2.3005

Ayu, C. C. M. (2018). Desain dan Media Pembelajaran Pendidikan Jasmani, Olahraga dan Kesehatan. Caremedia Communication.

Darmadi. (2017). Pengembangan Model dan Metode Pembelajaran dalam Dinamika Belajar Siswa. Deepublish.

Haryanto. (2012). Dr. Olahraga Mengenalkan Teknik Senam Dasar. PT Balai Pustaka (Persero).

Isnaini, L. M. Y. (2019). Aplikasi Latihan Mental Dalam Pembelajaran Gerak Untuk Meningkatkan Keterampilan Pada Pembelajaran Pendidikan Jasmani Olahraga dan Kesehatan. Jurnal Porkes, 2 (1), 17-25.

Jumesam, J., \& Hariadi, N. (2020). Pengembangan Model Pembelajaran Motorik Untuk Anak Sekolah Dasar. Jurnal Porkes, 3 (2), 119-126.

Lusiana. (2019). The Biomechanic Of Bridge Up Analysis. International Journal of Kinesiology and Physical Education, 1(2), 51-57. https://doi.org/10.34004/ijkpe.v1i1.15

Leuna, S., \& Fenanlampir, A. (2020). Meningkatkan Kemampuan Belajar Kopstand Melalui Metode Latihan Siswa Kelas X Sma Negeri 4 Ambon. Journal Pehr Sport (Physical Education, Health And Recreation), 1 (1), 19-26.

Lusiana, \& Purnama, Y. (2019). Skills of Penjasorkes Teacher Soft Skills Jepara MTS Working Group of 2019. Journal Of Sport Education (JOPE), 2 (1), 1-9.

Permana, R. (2020). Teori dan Praktik: Pendidikan Jasmani di Perguruan Tinggi (Zulfikar (ed.)). Edu Publisher.

Prakentristiari, N. K. L., Astra, I. K. B., \& Semarayasa, I. K. (2014). Penerapan Kooperatif Tipe Nht Untuk Meningkatkan Aktivitas Dan Hasil Belajar Senam Lantai. Jurnal Pendidikan Jasmani, Olahraga Dan Kesehatan Undiksha, 2 (1).

Sudjatmiko. (2021). Metode Tutor Sebaya (Peer Tutoring) dalam Pembelajaran di SMK. Penerbit Adab.

Saputra, H. P. P. (2017). Upaya peningkatan hasil belajar guling belakang senam lantai melalui model pembelajaran Student Team Achievement Division (STAD) pada siswa kelas XI B SMK TEKNO-SA Surakarta tahun ajaran 2016/2017.

Samsudin. (2008). Pembelajaran Pendidikan Jasmani Olahraga dan Kesehatan SMA. Jakarta: Literal.

Sutrisno \& Muhamad Bazin Khafadi (2010). Pendidikan Jasmani Olahraga Dan Kesehatan 2. Jakarta: Pusat Perbukuan Kemendiknas.

Suryani, Y., Rukmana, A., \& Sudirjo, E. (2018). Meningkatkan Pembelajaran Senam Kayang Menggunakan Metode Progresif. SpoRTIVE, 3 (1), 481-490.

Ulfah, M. (2018). Pengaruh Penerapan Model Cooperative Script Terhadap Hasil Belajar Siswa Di Mi Munawariyah Palembang (Doctoral Dissertation, Uin Raden Fatah Palembang).

Wardani. (2007). Penelitian Tindakan Kelas. Jakarta; Universitas Terbuka. 